\title{
CARACTERIZAÇÃO FISIOGRÁFICA DA SUB-BACIA DO RIO NATUBA - PE
}

\author{
Sara Fernandes de Souza ${ }^{1}$ \\ Maria do Socorro Bezerra de Araújoº \\ Ricardo Augusto Pessoa Braga ${ }^{3}$ \\ Carlos Eduardo Menezes da Silva ${ }^{4}$
}

Artigo recebido em 27/11/2008 e aceito para publicação em 25/03/2009.

\section{RESUMO}

O rio Natuba é o principal afluente da margem direita do rio Tapacurá, que por sua vez é estratégico manancial hídrico para a Região Metropolitana do Recife. Dando sequência aos estudos que vem sendo desenvolvidos na bacia do Tapacurá como um todo, com desdobramentos práticos para ações governamentais e da sociedade civil, estão sendo realizados na UFPE estudos hidrológicos, de solos e de uso sustentável da terra na sub-bacia do rio Natuba. Um passo importante para esses estudos é a caracterização fisiográfica da subbacia. Este trabalho oferece suporte de informação sobre hidrografia, geologia, relevo, solos, clima e vegetação local, incluindo os tipos de uso da terra.

Palavras-chave: Geoprocessamento, mapas, escalas.

\section{PHYSIOGRAPHY CHARACTERIZATION OF SUB-BASIN OF THE NATUBA - PE RIVER}

\begin{abstract}
The river Natuba is the main tributary of the right edge of the river Tapacurá and is a strategic hydric manantial for the Metropolitan Region of Recife. Giving sequence to the studies that are developed in the basin of the Tapacurá as a whole, with practical ramifications for government actions and those of the civil society, hydrological studies and those related to soils and the sustainable use of the land in the sub-basin of the river Natuba are being carried out in the UFPE. An important step for these studies is the physiographic characterization of the sub-basin. This work offers support of information on hydrography, geology, relief, soils, climate and local vegetation, including the types of use of the land.
\end{abstract}

Key words: Geoprocessment, maps, scales.

\footnotetext{
${ }^{1}$ Doutoranda do Programa de Pós-Graduação em Geografia do Departamento de Ciências Geográficas da Universidade Federal de Pernambuco (UFPE), Centro de Filosofia e Ciências Humanas. Avenida Professor Moraes Rego, 1235, Cidade Universitária, Recife, Pernambuco. CEP 50670-901 (sarinhafs@hotmail.com).

${ }^{2}$ Professora Adjunta do Programa de Pós-Graduação em Geografia do Departamento de Ciências Geográficas da Universidade Federal de Pernambuco (socorro@ufpe.com)

${ }_{3}^{3}$ Professor Adjunto do Programa de Pós-graduação em Engenharia Civil da Universidade Federal de Pernambuco (rbraga@hotlink.com.br).

${ }^{4}$ Mestrando do Programa de Pós-Graduação em Desenvolvimento e Meio Ambiente da Universidade Federal de Pernambuco (cadu_bio@yahoo.com.br).
} 


\section{RBGF- Revista Brasileira de Geografia Física}

Recife-PE Vol.01 n.02 Set/Dez 2008,1-14

\section{INTRODUÇÃO}

A bacia hidrográfica do rio Tapacurá é de grande importância estratégica para a Região Metropolitana do Recife, uma vez que é manancial para abastecimento público de mais de um milhão de habitantes, por meio do reservatório da barragem do Tapacurá. Portanto, as atividades humanas, rurais e urbanas, que se estabelecem a montante do reservatório, têm o potencial de comprometer o abastecimento público metropolitano. Assim, as casas de farinha, matadouros, despejos de esgotos domésticos, usos de agrotóxicos e o mau uso da terra, provocando erosão, são fatores que condicionam a qualidade da água. Ao mesmo tempo os desmates afetam o regime de vazão das águas da sub-bacia do Natuba e da bacia do rio Tapacurá.

Atentos a esses processos, professores da UFPE elaboraram um diagnóstico ambiental da bacia do Tapacurá e, em seguida, estruturam um Plano de Gestão Ambiental para a bacia (Braga et al., 2001). Em decorrência, vários outros projetos vêm sendo desenvolvidos, tanto pela academia quanto pelos governos e entidades organizadas da sociedade civil.

Dando prosseguimento aos estudos na bacia do Tapacurá foram iniciados trabalhos também na sub-bacia do rio Natuba. Esta possui cinco assentamentos rurais e é produtora de água tanto para o município de Vitória de Santo Antão quanto para o reservatório do rio Tapacurá. Observe-se ainda que a intensa atividade agrícola de horticultura que ocorre na subbacia decorre de natural disponibilidade de água local, que precisa ser conservada, juntamente com a capacidade produtiva dos solos.

Nesta perspectiva, o Laboratório de Geografia Física do Departamento de Geografia da UFPE, em parceria com o grupo de Recursos Hídricos do Departamento de Engenharia Civil da mesma universidade, está estudando as relações hidrológicas e pedológicas que estão ocorrendo, em decorrência dos diferentes usos econômicos da terra. Para isso um passo importante é a caracterização fisiográfica da sub-bacia do rio Natuba.

Neste sentido, este trabalho oferece o suporte com as informações já produzidas facilitando os novos projetos que se iniciam.

\section{MATERIAL E MÉTODOS}

A área de estudo foi a sub-bacia do rio Natuba, localizada nos municípios de Vitória de Santo Antão e Pombos, no 


\section{RBGF- Revista Brasileira de Geografia Física \\ Recife-PE Vol.01 n.02 Set/Dez 2008,1-14}

estado de Pernambuco. Foram utilizadas as bases de dados da hidrografia, altimetria, uso do solo e clima da bacia do rio Tapacurá nas escalas de 1: 25.000, 1: 50.000 e 1:100.000, elaborados no Projeto Gestão Ambiental da Bacia do Tapacurá (BRAGA, 2001), os quais serviram de base para a elaboração do Modelo Digital de Elevação e Declividade do Terreno. A Geologia foi obtida através dos dados do projeto Geologia e Recursos Minerais do Estado de Pernambuco, na escala de 1:500.000 (Gomes e Santos, 2001), e os tipos de Solos, a partir do Zoneamento Agroecológico do Estado de Pernambuco (Silva et al. 2001), na escala de 1:100.000.

Para a confecção do mapa de vegetação densa da sub-bacia do rio Natuba foi utilizada a técnica da Análise por Componentes Principais - ACP, segundo a metodologia descrita por Maldonado (1999). A ACP foi aplicada sobre a composição das bandas 3 e 4 de cada imagem para se obter a quantidade de vegetação densa existente na área. A análise por componentes principais é considerada como uma das funções mais poderosas de processamento de imagens em relação à manipulação de dados multitemporais.

A caracterização fisiográfica da sub-bacia do rio Natuba foi elaborada por meio da geração de planos de informação com o auxílio do programa ArcGIS 9.1, disponível no Departamento de Ciências Geográficas da Universidade Federal de Pernambuco.

\section{RESULTADOS E DISCUSSÃO}

Localização da área - A sub-bacia do rio Natuba localiza-se na Zona da Mata Centro do Estado de Pernambuco, abrangendo os municípios de Vitória de Santo Antão e Pombos, inserindo-se na bacia hidrográfica do rio Tapacurá (Fig. 1), sendo o principal afluente da sua margem direita (Braga et al, 2001).

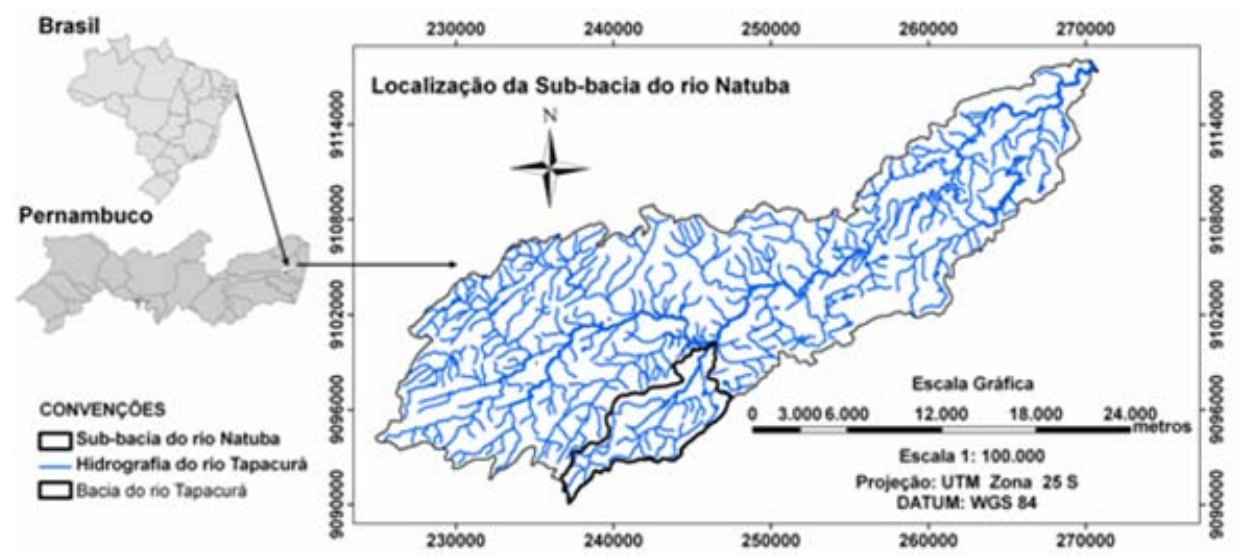

Figura 1 - Localização da sub-bacia do rio Natuba inserindo-se na bacia hidrográfica do rio Tapacurá.

Souza, S. F. de., Araújo, M. do S. B., Braga, R. A. P., Silva, C. E. M. da. 
Hidrografia - A sub-bacia hidrográfica do rio Natuba possui uma área de drenagem de aproximadamente $39 \mathrm{~km}^{2}$ (3.874,08 ha), que correspondem a 8,23\% da área da bacia do Tapacurá (Fig. 2). O seu curso principal, com extensão de 17,5 km, possui um afluente na sua margem esquerda com comprimento de aproximadamente 1,6 km e 24 afluentes na margem direita, que totalizam 39,6 km de cursos d’água (Silva, 2007). A nascente do curso principal localiza-se no interior do fragmento da Mata do Ronda na região do Alto Natuba nas coordenadas 0237280 E $9090994 \mathrm{~N}$ (Silva, 2007). A Tab. 1 apresenta as características morfométricas da sub-bacia do rio Natuba.

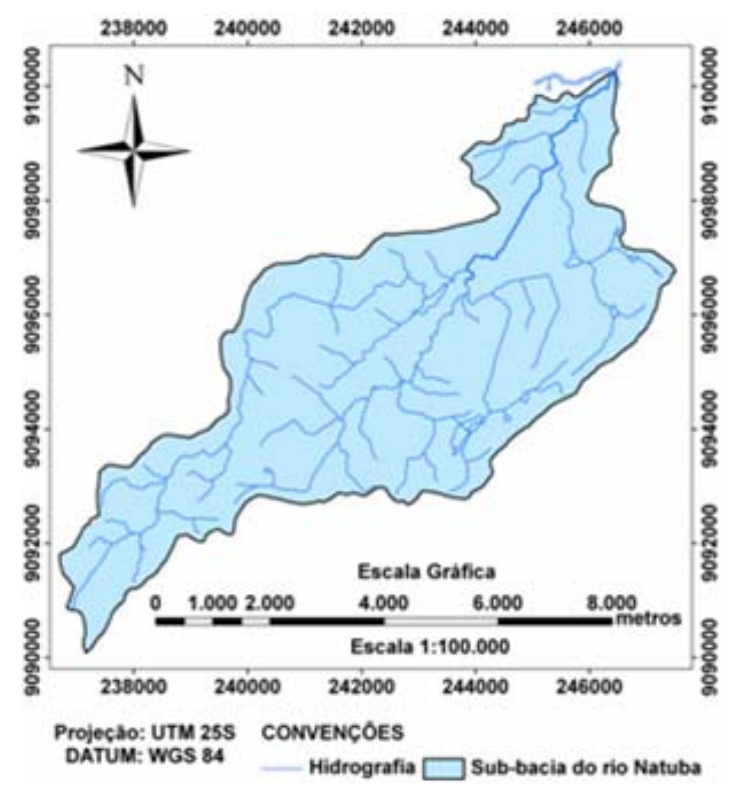

Figura 2 - Hidrografia da Sub-bacia do rio Natuba, localizada na Zona da Mata Centro do Estado de Pernambuco. Fonte: Adaptado de Braga, 2001.

O Alto Natuba possui uma área de 5,95 $\mathrm{km}^{2}$, correspondendo a 15,34\% do território da sub-bacia; o Médio Natuba possui uma área de 23,74 $\mathrm{km}^{2}$, correspondendo a 61,15\% do território da sub-bacia do rio Natuba; enquanto o Baixo
Natuba apresenta-se com área de 9,05 km², correspondendo a 23,51\% da área total. (Silva, 2007). A Tab. 2 apresenta informações mais detalhadas sobre esse segmento.

Tabela 1 - Características morfométricas da bacia do Natuba (Silva, 2007). 
RBGF- Revista Brasileira de Geografia Física

Recife-PE Vol.01 n.02 Set/Dez 2008,1-14

\begin{tabular}{cc}
\hline Características & Valor/Unidade \\
Área & $3.874,08 \mathrm{ha}\left(38,74 \mathrm{~km}^{2}\right)$ \\
Comprimento total dos canais & $41,14 \mathrm{~km}$ \\
Comprimento do curso principal & $17,5 \mathrm{~km}$ \\
Comprimento dos afluentes da margem direita & $39,56 \mathrm{~km}$ \\
Comprimento dos afluentes da margem esquerda & $1,6 \mathrm{~km}$ \\
Densidade de drenagem & $1,51 \mathrm{~km} / \mathrm{km}{ }^{2}$ \\
Altitude máxima na bacia & $520 \mathrm{~m}$ \\
Altitude na nascente do curso principal & $520 \mathrm{~m}$ \\
Altitude no exutório & $150 \mathrm{~m}$ \\
Desnível da nascente ao exutório & $370 \mathrm{~m}$ \\
Índice de declividade global & $0,02114 \mathrm{~m} / \mathrm{m}$
\end{tabular}

Tabela 2 - Extensão e área de drenagem das sub-bacias do Natuba (Silva, 2007).

\begin{tabular}{cccccc}
\hline Trechos & $\begin{array}{c}\text { Extensão curso } \\
\text { principal (Km) }\end{array}$ & $\begin{array}{c}\text { Extensão } \\
\text { afluentes } \\
(\mathrm{Km})\end{array}$ & $\begin{array}{c}\text { Extensão } \\
\text { total dos } \\
\text { cursos } \\
\text { d'água } \\
(\mathrm{Km})\end{array}$ & $\begin{array}{c}\text { Área de } \\
\text { drenagem } \\
(\text { ha })\end{array}$ & $\begin{array}{c}\text { Percentual } \\
\text { área total } \\
\text { da bacia } \\
\text { (\%) }\end{array}$ \\
\hline Alto Natuba & 4,62 & 4,4 & 9,02 & 594,87 & 15,34 \\
Médio Natuba & 7,86 & 29,39 & 37,25 & 2373,7 & 61,15 \\
Baixo Natuba & 5,01 & 7,35 & 12,36 & 905,51 & 23,51 \\
\hline Total & 17,49 & 41,14 & 58,63 & 3874,08 & 100 \\
\hline
\end{tabular}

O uso da água se dá sobretudo para a irrigação e abastecimento públicos, realizados sem o planejamento adequado, constituindo-se em elementos de pressão sobre os recursos hídricos, o que pode contribuir para a redução da qualidade da água, e da sua da disponibilidade, tanto para subsistência das populações locais, que têm na agricultura irrigada 


\section{RBGF- Revista Brasileira de Geografia Física \\ Recife-PE Vol.01 n.02 Set/Dez 2008,1-14}

sua principal atividade econômica, como em escala regional, dada a importância da bacia do Tapacurá (Silva, 2007).

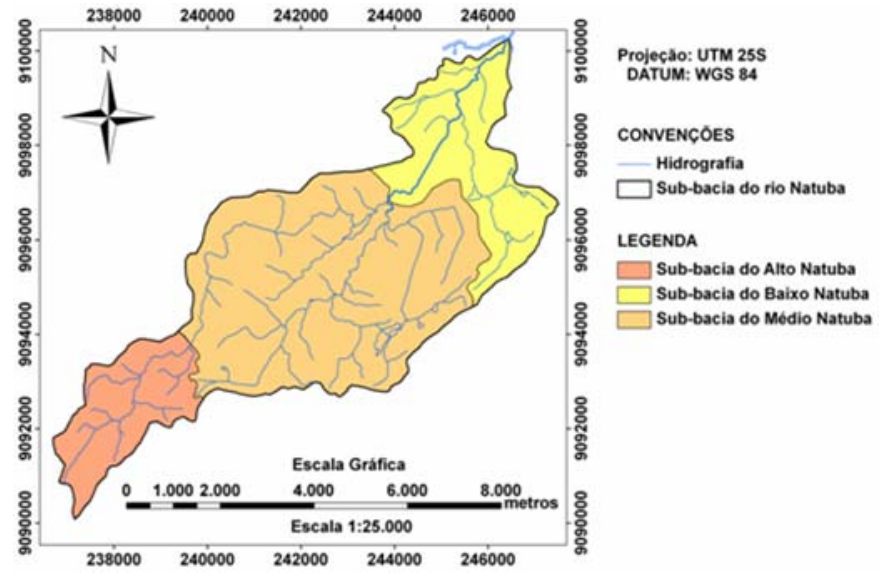

Figura 3 - Localização das sub-bacias do Alto, Médio e Baixo Natuba, abrangendo os municípios de Vitória de Santo Antão e Pombos, Zona da Mata Centro do Estado de Pernambuco. Fonte: Adaptado de Braga, 2001.

Geologia - Segundo Gomes e Santos, 2001 a sub-bacia do rio Natuba está inserida nos complexos geológicos de: My4sm, Mbf, NY3m, Ny3qd (Fig. 4).

- My4sm: rochas metaplutônicas (mesoproterozóica) compostas por leucogranitóides contendo biotita e muscovita.

- Mbf: Complexo Belém de São Francisco (mesoproterozóico) formadas por biotita ortognaisses tonalíticos/granodioríticos, leucocrático de cor cinza, geralmente migmatizados e migmatitos com mesossoma quartzo diorítico/tonalítico a anfibólio e/ou biotita, etc.

- NY3m: Suíte Magmática (neoproterozóico) compostos por monzonitos e granodioritos com enclaves máficos/filiação alcalinametaluminosa.

Ny3qd: Suítes Magmáticas (neoproterozóico) formados por quartzodioritos com variações para monzodioritos, monzogranitos e biotitagranodioritos. 


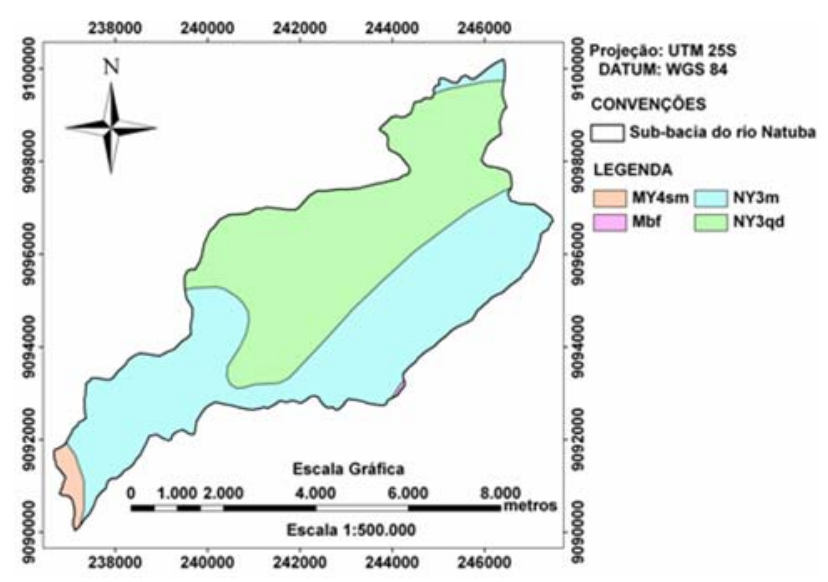

Figura 4 - Complexos geológicos da sub-bacia do rio Natuba, abrangendo os municípios de Vitória de Santo Antão e Pombos, Zona da Mata Centro do Estado de Pernambuco. Fonte: Gomes e Santos, 2001.

Relevo - O rio Natuba possui cotas altimétricas entre 160 a 570 metros (Tab. 3), havendo assim uma diferença de 410 metros entre o ponto mais alto e o mais baixo da sub-bacia (Fig. 5 e 6).

Tabela 3 - Classes da altimetria (\%) da sub-bacia do rio Natuba.

\begin{tabular}{cccc}
\hline Classes de Altitude & Área (\%) & Classes de Altitude & Área (\%) \\
\hline $160-200$ & 3,80 & $360-400$ & 19,02 \\
$200-240$ & 2,72 & $400-440$ & 31,52 \\
$240-280$ & 3,26 & $440-480$ & 3,26 \\
$280-320$ & 11,41 & $480-520$ & 3,26 \\
$320-360$ & 11,97 & $520-570$ & 9,78 \\
\hline
\end{tabular}


RBGF- Revista Brasileira de Geografia Física

Recife-PE Vol.01 n.02 Set/Dez 2008,1-14

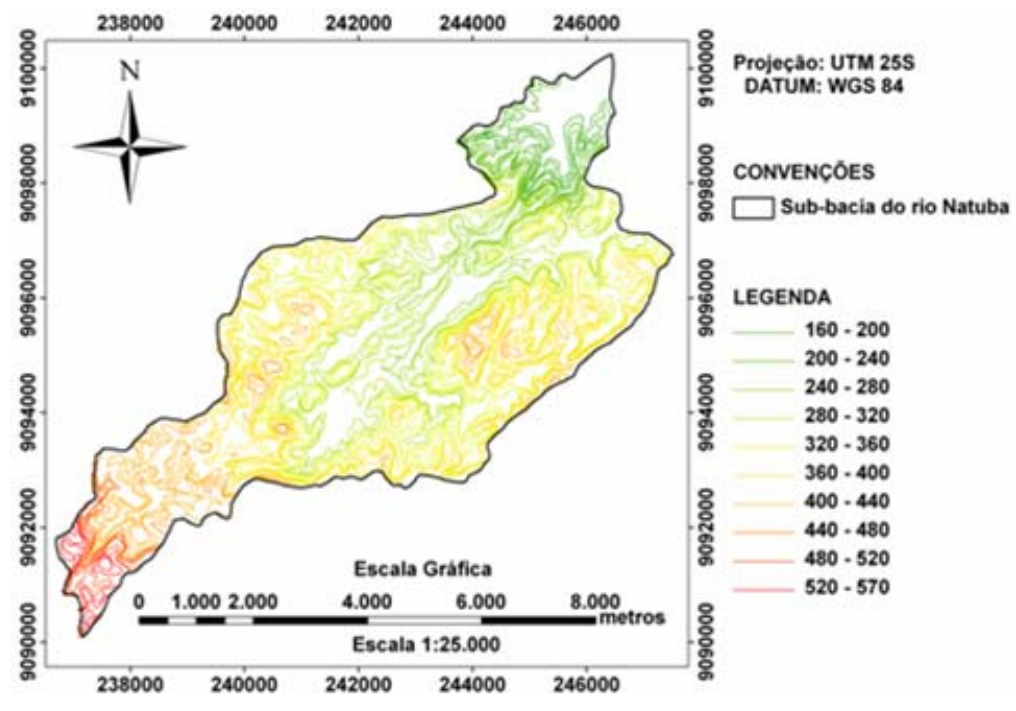

Figura 5 - Altimetria da sub-bacia do rio Natuba, abrangendo os municípios de Vitória de Santo Antão e Pombos, Zona da Mata Centro do Estado de Pernambuco. Fonte: Adaptado de Braga, 2001.

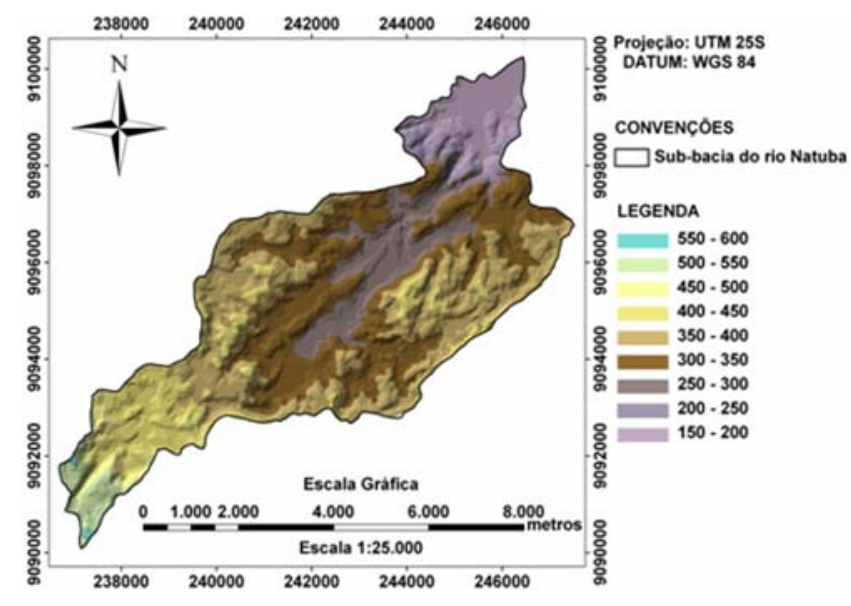

Figura 6 - Modelo Digital de Elevação do terreno da sub-bacia do rio Natuba, abrangendo os municípios de Vitória de Santo Antão e Pombos, Zona da Mata Centro do Estado de Pernambuco.

A Tab. 4 apresenta as classes de declividade da área, baseadas na classificação de Capacidade de Uso das
Terras do Conama, segundo a resolução $n^{\circ}$ 289, com consequente mapa de declividade apresentada.

Tabela 4 - Classes da declividade (\%) na sub-bacia do rio Natuba, baseadas na Resolução do CONAMA n ${ }^{\circ}$ 289/01. 
RBGF- Revista Brasileira de Geografia Física

Recife-PE Vol.01 n.02 Set/Dez 2008,1-14

\begin{tabular}{ccc}
\hline Classes de Relevo & Classes de Declividade (\%) & Área (\%) \\
\hline Plano & $0-5$ & 34,47 \\
Suave Ondulado & $5-10$ & 20,04 \\
Ondulado & $10-15$ & 14,44 \\
Muito Ondulado & $15-25$ & 21,10 \\
Forte Ondulado & $25-47$ & 9,95 \\
Áreas de Uso Restrito & $47-100$ & 0,00 \\
Área de Preservação Permanente & $>100$ & 0,00 \\
\hline
\end{tabular}

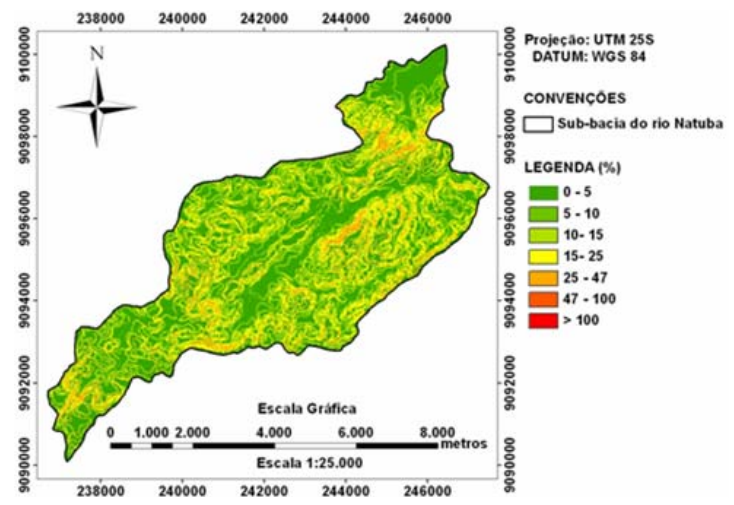

Figura 7 - Declividade (\%) da sub-bacia do rio Natuba, abrangendo os municípios de Vitória de Santo Antão e Pombos, Zona da Mata Centro do Estado de Pernambuco. Fonte: Adaptado de Braga, 2001.

Solos - Segundo Silva et al. (2001), os principais tipos de solos ocorrentes na sub-bacia do rio Natuba são o Latossolo Amarelo, Argissolo Amarelo, Argissolo Vermelho e o Gleissolo (Fig. 8). De acordo com a EMBRAPA (2006) o Latossolo, Argissolo e o Gleissolo são definidos como:

- Latossolo: solos formados por material mineral, com horizonte $\mathrm{B}$ latossólico prontamente abaixo de qualquer um dos tipos de horizonte diagnóstico superficial, exceto hístico.

o Latossolo Amarelo: solos com matiz 7,5YR ou mais amarelo na parte dos primeiros $100 \mathrm{~cm}$ do horizonte B (inclusive BA).

- Argissolo: solos formados por material mineral com argila de baixa atividade ou alta, combinada com saturação de bases baixa ou 


\section{RBGF- Revista Brasileira de Geografia Física}

Recife-PE Vol.01 n.02 Set/Dez 2008,1-14

caráter alítico, e horizonte B

textural rigorosamente abaixo de horizonte A ou E.

o Argissolo Amarelo: solos com matiz 7,5 YR ou mais amarelos na maior parte do primeiro metro do horizonte B (inclusive BA).

o Argissolo Vermelho: solos com matiz 2,5YR ou mais vermelho ou com matiz 5YR e valores e cromos iguais ou menores que 4, na maior parte do primeiro metro do horizonte $\mathrm{B}$ (inclusive BA).

- Gleissolo: solos constituídos por material mineral compreendendo-se como hidromórficos, onde apresentam logo abaixo do horizonte $\mathrm{A}$ ou $\mathrm{E}$, ou $\mathrm{H}$ um horizonte glei dentro de $1,5 \mathrm{~m}$ da superfície.

A Tab. 5 apresenta as áreas das classes de solo na sub-bacia do rio Natuba, baseada também em de Silva et al. (2001).

Tabela 5 - Área das classes de solo da sub-bacia do rio Natuba, Zona da Mata Centro do Estado de Pernambuco.

\begin{tabular}{lcc}
\hline \multicolumn{1}{c}{ Classes de Solos } & Área $\left(\mathrm{km}^{2}\right)$ & Área (\%) \\
\hline Latossolo Amarelo & 1,81 & 0,91 \\
Argissolo Amarelo & 103,62 & 51,91 \\
Argissolo Vermelho & 86,63 & 43,40 \\
Gleissolo & 7,56 & 3,78 \\
\hline
\end{tabular}

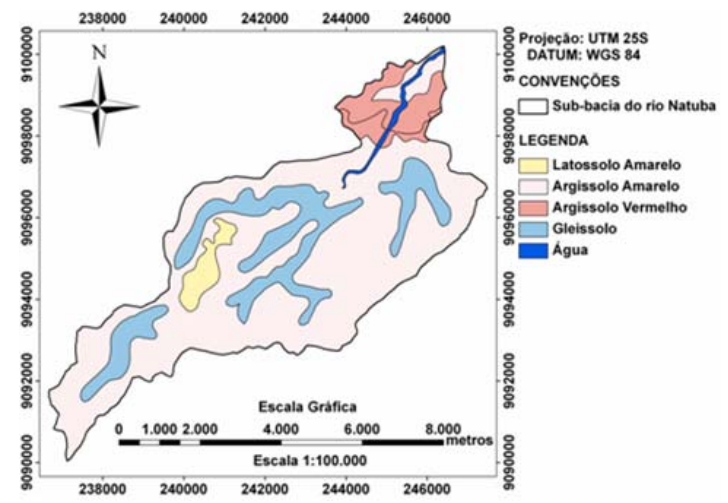

Figura 8 - Mapa de Solo da sub-bacia do rio Natuba, abrangendo os municípios de Vitória de Santo Antão, Zona da Mata Centro do Estado de Pernambuco. Fonte: Adaptado de Silva et al. (2001).

Souza, S. F. de., Araújo, M. do S. B., Braga, R. A. P., Silva, C. E. M. da. 


\section{RBGF- Revista Brasileira de Geografia Física \\ Recife-PE Vol.01 n.02 Set/Dez 2008,1-14}

Clima - O clima local é denominado como Tropical chuvoso ou Megatérmico úmido, com período chuvoso de março a julho (outono-inverno) e temperatura média anual de $23,8^{\circ} \mathrm{C}$, variando entre a mínima de $19,3^{\circ} \mathrm{C}$ e a máxima de $30,9^{\circ} \mathrm{C}$ (Silva, 2007).

De acordo com os dados pluviométricos dos postos de Vitória de Santo Antão e Engenho Serra Grande, a área apresenta uma precipitação média anual entre $1.008 \mathrm{~mm}$ e $1395 \mathrm{~mm}$, com o período chuvoso entre os meses de março a julho, ou seja, chuvas de outono-inverno, concentrando-se nessa estação em torno de 70\% da precipitação média anual (Braga et al.,1998).

A área de estudo encontra-se em uma zona de transição entre a Mata pernambucana e o Agreste, apresentando características mais úmidas a leste e mais secas a oeste da região.

Vegetação e uso da terra - A vegetação nativa da sub-bacia do rio Natuba é caracterizada por dois tipos distintos: Mata Atlântica, representada por um importante remanescente conhecido como Mata do Ronda, que possui cerca de 512 ha de extensão, e a Caantiga, que é encontrada nas escarpas da Serra das Russas (Braga, 2005).

A cobertura vegetal de Mata Atlântica foi em grande parte degradada devido à expansão da monocultura da cana-de-açúcar, a qual a partir do inicio da década de 1990, com a crise canavieira, foram gradativamente substituídos pela horticultura folhosa (Braga et al.,1998).

A Fig. 9 apresenta a cobertura vegetal densa da sub-bacia do rio Natuba para o ano de 2007. A cobertura vegetal densa corresponde a 33,97\% do total da região. Essa cobertura vegetal está concentrada nas áreas provavelmente relacionadas às atividades econômicas locais ligadas ao uso da terra (agricultura, pecuária, silvicultura) e ao surgimento de áreas de reserva ambiental, corroborando com os resultados apresentados por Silva (2006), no estudo intitulado "Uso e ocupação do solo em áreas de preservação permanente da bacia hidrográfica do Natuba, afluente do Tapacurá - PE”, onde foi diagnosticado que as principais atividades econômicas na área são a agricultura e pecuária. Também havendo a detecção de áreas de preservação de fragmentos florestais.

As formas de utilização da terra na região da sub-bacia do rio Natuba foram 


\section{RBGF- Revista Brasileira de Geografia Física}

Recife-PE Vol.01 n.02 Set/Dez 2008,1-14

classificadas, segundo Braga (2001), como

de: mata, capoeira, cana-de-açúcar, horticultura, policultura, fazendas e superfície de água (Fig. 10).



Figura 9 - Vegetação densa da sub-bacia do rio Natuba, abrangendo os municípios de Vitória de Santo Antão, Zona da Mata Centro do Estado de Pernambuco.

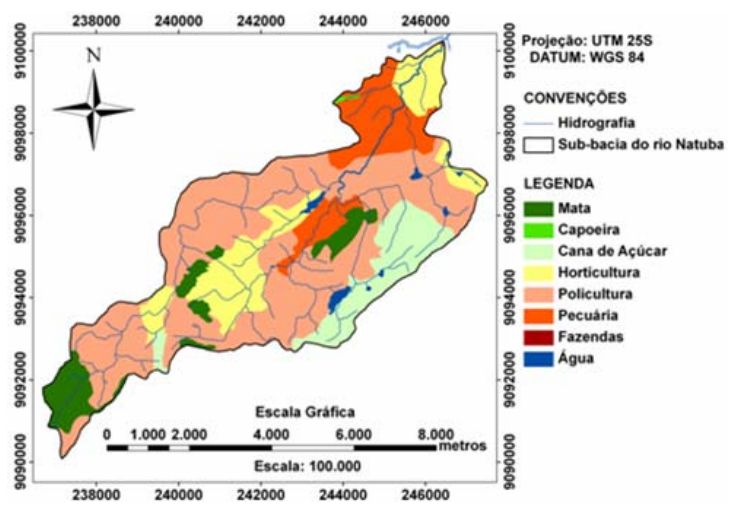

Figura 10 - Uso da terra da sub-bacia do rio Natuba, abrangendo os municípios de Vitória de Santo Antão, Zona da Mata Centro do Estado de Pernambuco. Fonte: Braga (2001).

\section{CONCLUSÃO}

A partir dos dados disponiveis em diversas fontes foi possivel construir um banco de dados geográficos para a área de estudo. No entanto, uma das dificuldades encontradas relaciona-se às diferentes escalas dos dados originais, que variaram de 1:500.000, até 1:25.000. Para a geração de um banco de dados mais preciso, será necessário atualização e adequação das escalas das informações originais e a inserção de novos parâmetros de informação como matéria orgânica do solo, erodibilidade, erosividade, dentre outros. Todavia, o 


\section{RBGF- Revista Brasileira de Geografia Física}

Recife-PE Vol.01 n.02 Set/Dez 2008,1-14

trabalho é de grande relevância para o estudo da sub-bacia do rio Natuba, pois servirá de base para próximas pesquisas na região.

\section{AGRADECIMENTOS}

Ao Programa de Pós-Graduação em Geografia (PPGEO) da Universidade Federal de Pernambuco (UFPE) e à Fundação de Amparo à Ciência e a Tecnologia do Estado de Pernambuco (FACEPE), pela concessão de bolsa de estudo.

\section{REFERÊNCIAS}

BRAGA, R. A. P.; PATRÍCIO, F.; PASSOS, F.; SANGUINETTI, M.; CABRAL, J.; COSTA, M. C. Subsídios para o Gerenciamento Ambiental da Bacia Hidrográfica do Tapacurá. In: IV SIMPÓSIO DE RECURSOS HÍDRICOS DO NORDESTE, 10., Campina Grande. Anais. 1998.

BRAGA, R. A. P. Gestão Ambiental da Bacia do Rio Tapacurá - Plano de Ação. Universidade Federal de Pernambuco/ CTG/ DECIVIL / GRH; Recife: Ed. Universitária da UFPE, 2001. 101p.
BRAGA, R. A. P. Carta Consulta ao PROMATA (Projeto): Recuperação e Produção Agroflorestal no Assentamento de Ronda - Pombos. Sociedade Nordestina de Ecologia. Recife 2005. 22p.

CONAMA - Conselho Nacional de Meio Ambiente. Resolução $\mathrm{n}^{0}$ 289, de 25 de outubro de 2001. Estabelecendo diretrizes para o licenciamento ambiental de projetos de assentamentos de reforma agrária.

EMBRAPA - Empresa Brasileira de Pesquisa Agropecuária: Centro Nacional de Pesquisa de Solos, Rio de Janeiro, 2006. Sistema Brasileiro de Classificação de Solos. $2^{\circ}$ ed. 306 p.

GOMES, H. A. \& SANTOS, E. J. (org). Geologia e Recursos Minerais do Estado de Pernambuco. Recife: CPRM, 2001. 214 p.

MALDONADO, F. D. Análise por Componentes Principais (ACP) na caracterização da dinâmica do uso da terra em área do semi-árido brasileiro: Quixaba-PE. Dissertação (Mestrado em Sensoriamento Remoto) INPE, São José dos Campos, 1999.

SILVA, C. E. M. Programa de Adequação Ambiental e Proposta de Pagamento por 
Serviços Ecossistêmicos no Assentamento

Chico Mendes (Ronda), Microbacia do Alto Natuba, afluente do Tapacurá Pombos -PE. Monografia de graduação. Centro Federal de Educação Tecnológica de Pernambuco. Recife, 2007.

SILVA, F. B. R.; SILVA, M. A. V.; BARROS, A. H. C.; SANTOS, J. C. P.; SILVA, A. B.; CAVALCANTI, A. C.; SILVA, F. H. B. B.; BURGOS, N.; PARAHYBA, R. B. V.; OLIVEIRA
NETO, M. B.; SOUZA NETO, N. C.; ARAÚJO FILHO, J. C.; LOPES, O. F.; LUZ, L. R. Q. P.; LEITE, A. P.; COSTA, L. G. M.; SILVA, C. P. Zoneamento Agroecológico de Pernambuco - ZAPE. Unidade de Execução de Pesquisa e Desenvolvimento - UEP; Governo do Estado de Pernambuco (Secretaria de Produção Rural e Reforma Agrária). (Embrapa Solos. Documentos; no. 35). Recife, 2001. CD-ROM. 